This item was submitted to Loughborough's Research Repository by the author.

Items in Figshare are protected by copyright, with all rights reserved, unless otherwise indicated.

\title{
Chronology of drought termination for long records in the Thames catchment
}

PLEASE CITE THE PUBLISHED VERSION

http://dx.doi.org/10.1201/b18077-28

PUBLISHER

(c) Taylor \& Francis

VERSION

AM (Accepted Manuscript)

\section{PUBLISHER STATEMENT}

This work is made available according to the conditions of the Creative Commons Attribution-NonCommercialNoDerivatives 4.0 International (CC BY-NC-ND 4.0) licence. Full details of this licence are available at: https://creativecommons.org/licenses/by-nc-nd/4.0/

\section{LICENCE}

CC BY-NC-ND 4.0

\section{REPOSITORY RECORD}

Parry, Simon, Christel Prudhomme, Robert L. Wilby, and Paul J. Wood. 2019. "Chronology of Drought Termination for Long Records in the Thames Catchment". figshare. https://hdl.handle.net/2134/18597. 


\title{
Chronology of drought termination for long records in the Thames catchment
}

\author{
S. Parry \\ Centre for Ecology \& Hydrology, Wallingford, Oxfordshire, UK \\ Loughborough University, Loughborough, Leicestershire, UK \\ C. Prudhomme \\ Centre for Ecology \& Hydrology, Wallingford, Oxfordshire, UK \\ R. Wilby \& P. Wood \\ Loughborough University, Loughborough, Leicestershire, UK
}

\begin{abstract}
Drought termination has been relatively neglected in the scientific literature, despite its importance for water resource managers and the often disruptive nature of this transitional period. There is a pressing need to systematically assess the nature of drought termination events in the historical record, and the use of long records potentially provides valuable information on the mechanisms of recovery. In this study, a novel approach for objectively defining and characterizing drought termination is applied to long records of river flow and groundwater level in the River Thames catchment. Chronologies of hydrological and groundwater drought termination are presented for 1883-2013 and 1933-2013, respectively. The chronologies show good agreement with known historical drought termination events, and examination of associated metrics allows the quantification of termination characteristics previously not possible. The parallel application to river flow and groundwater level data enables the assessment of propagation of drought termination through the hydrological cycle.
\end{abstract}

\section{INTRODUCTION}

Drought termination, defined generally as the end of drought conditions, has been relatively neglected in the scientific literature. This is despite the fact that droughts tend to end abruptly (Dettinger 2013), frequently causing significant disruption (e.g. Parry et al. 2013). However, the frequency of abrupt drought terminations may be overestimated, perhaps because they are more dramatic and newsworthy than a gradual return to 'normal conditions'. The terminal phase is also the point during a drought when water resources are most stretched, and when information on the likelihood of termination would be most welcome. A more comprehensive understanding of drought termination would improve our knowledge of its physical processes and represents a potentially important contribution to drought monitoring and forecasting activities.

The concept of drought termination prevalent in the literature is an instantaneous point in time which sub-divides 'drought' and 'normal' conditions, separated by a criterion that determines whether termination has occurred, but this approach ignores the termination phase (Byun \& Wilhite 1999). Current knowledge of why and how a drought ends has been constrained by limitations of indices and methods (Panu \& Sharma 2002; Heim Jr. \& Brewer 2012).

Attempts to systematically assess the end of drought generally have focused on the impact of a specific driver of the recovery from drought, such as tropical cyclones (e.g. Kam et al. 2013) or atmospheric rivers (e.g. Dettinger 2013) terminating drought in the United States (US). These phenomena are the dominant 'drought busting' factors in coastal areas of the US, but the focus of these studies is assessing the proportion of droughts that are terminated by these drivers.

Long hydrometric records provide the best indicator of the spectrum of possible drought termination characteristics. Whilst long records are relatively rare in global terms (Bayliss et al. 2004), some data in the United Kingdom (UK) extend back into the $19^{\text {th }}$ century and earlier, including datasets of rainfall (e.g. Alexander \& Jones 2001), temperature (e.g. Manley 1974), observed and reconstructed river flows (e.g. Jones et al. 2006) and groundwater levels. These long 
records allow an investigation of pre-industrial conditions and provide a long-term perspective on shorter-term trends (Hannaford \& Buys 2012). The Thames catchment is one of the most extensively studied in the world (Marsh \& Harvey 2012), at least in part due to the long and complete time series of river flow data available. This range of long observed and reconstructed hydrometeorological records has been capitalized upon in analyzing natural variability, trends and extreme events (e.g. Jones et al. 2006).

This paper describes a new approach to defining and characterizing drought termination. Chronologies of drought termination are then presented, alongside a discussion of their validity and a comparison between hydrological and groundwater termination characteristics. This paper will assess hydrological and groundwater drought termination identified in 'continuous' river flow and groundwater level data. Application of the methodology to 'discrete' data (e.g. rainfall totals) is less straightforward, and the concept of meteorological drought differs from that of hydrogeological drought, which is influenced by the role of storage.

\section{DATA}

With a catchment area of $9,948 \mathrm{~km}^{2}$ to its tidal limit in west London, the River Thames is the largest basin in the UK. The flow regime is influenced by a range of hydrogeological formations, from responsive areas of clay to slow responding outcrops of chalk and limestone. The Thames has a long history of changing land use and river flow management, and the basin has witnessed large population increases in urban centers that have put pressure on water resources. The flow record at Kingston, close to the tidal limit, dates back to 1883, making it one of the longest complete river flow records in the world. The hydrometry has changed significantly over time, but the series remains incredibly valuable. The degree of abstractions within the catchment requires the flow data to be naturalized to remove the human influences (Marsh \& Harvey 2012). This study uses monthly mean naturalized flows from 1883-2013. The Rockley borehole monitors the Cretaceous Chalk in the south-west of the Thames catchment. The Chalk aquifer at this location is unconfined, and levels typically fluctuate by around $12 \mathrm{~m}$ over the annual cycle. Levels have been recorded weekly from 1933 to present. This study uses monthly mean groundwater levels from 1933-2013.

\section{DEFINING DROUGHT TERMINATION}

\subsection{A novel approach}

Characterization of drought termination requires the identification of its start (the end of the preceding drought) and end (when recovery is complete). Whilst most concepts of drought termination do not account for this, Mo (2011) introduced a 'transition time' at the end of a drought and Bonsal et al. (2011) suggested the partitioning of drought into six distinct parts, one of which is a 'recovery' phase. The approach described below builds upon these concepts.

\subsection{Defining and characterizing drought termination}

The method can be applied to a range of time steps (e.g. daily, monthly), expressed as a percentage anomaly of the long-term average (for a standard reference period, e.g. 1971-2000). The metrics introduced below are illustrated in Figure 1.

1) Start of drought ('droughtStart') is the beginning of a period of below-threshold anomalies (site-specific criterion). The possible inclusion of time steps with above-threshold anomalies amongst the below-threshold anomalies (site-specific criterion) allows for storm events in the middle of a drought.

2) End of termination ('termEnd') is the end of a period of consecutive above-threshold anomalies (site-specific criterion). The recovery threshold ('recovThresh') is the 
above-threshold anomaly for the last of these consecutive time steps, indicating the recovery has been sustained above the threshold for longer than an intermittent storm.

3) Drought development and termination phases are partitioned at the time step corresponding to the largest below-threshold anomaly (the drought magnitude; 'droughtMagn'). This time step is the end of drought ('droughtEnd'), and the following time step is the start of termination ('termStart').

4) Termination duration ('termDur') is the number of time steps between the start and end of the termination. Drought duration ('droughtDur') is the same but for the drought.

5) Termination rate ('termRate') is calculated as the difference between the drought magnitude and the recovery threshold (i.e. the change from the drought minimum to the end of recovery), divided by the 'termDur'. This indicates the 'gradient' of recovery (Figure 1). Metrics are derived from percentage anomaly data, so the unit of 'termRate' is percent per time step.

6) Termination seasonality ('termSeas') classifies the period over which drought termination occurs as spring, summer, autumn, winter, or a combination of these (Figure 1).

Figure 1. Conceptual diagram of drought termination metrics. The grey horizontal line represents a user-defined threshold and the black stepped line represents observations.

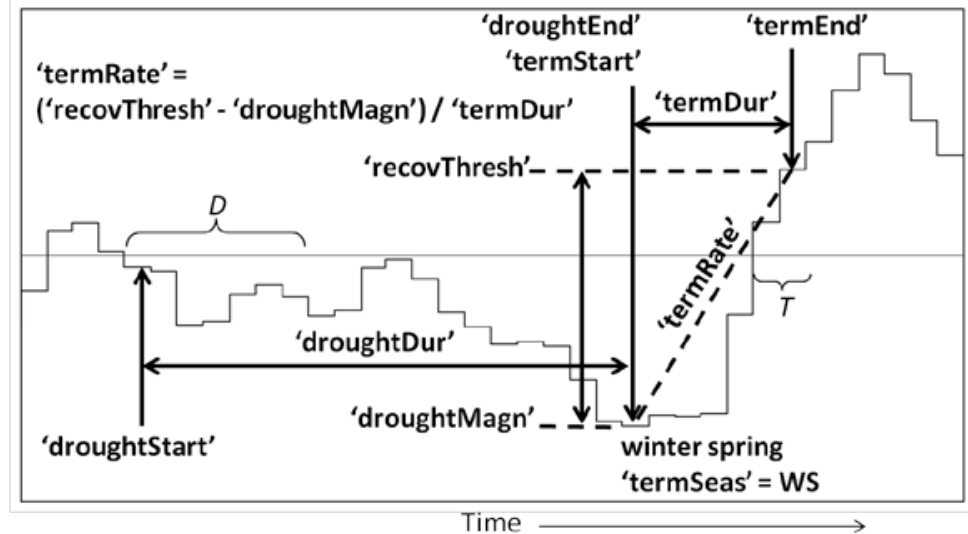

This approach to defining and characterizing drought termination has been applied to the monthly Kingston river flow and Rockley groundwater level data. Chronologies of drought termination in the Thames catchment are presented in Figure 2 and Figure 3.

\section{DISCUSSION}

\subsection{Validating the chronologies}

Major droughts in England and Wales occurred in 1887-1888, 1890-1910, 1921-1922, 19331934, 1959, 1976, 1990-1992, 1995-1997 and 2004-2006 (Marsh et al. 2007, identified using hydrological and documentary evidence). Almost all of these events are detected in the chronologies shown in Figure 2 and Figure 3, as is the most recent severe drought in 2010-2012 (Kendon et al. 2013). Notably, the 1959 drought is not detected in either of the chronologies, although this event occurred predominantly in eastern and central parts of England and had little expression in groundwater influenced areas of the south-east (Marsh et al. 2007), including the Thames. The 'Long Drought' of 1890-1910 is particularly noticeable in Figure 2 as a period during which pairs of drought and termination occurred almost continuously. This identifies a succession of droughts with some wet interludes that allowed termination to be complete, but with drought conditions returning almost immediately. The most severe phases of the drought (1893, 1899, 1902, 1905) and the extreme wetness of 1903 (Marsh et al. 2007) are largely reproduced in Figure 2. The 'Long Drought' had a significant impact on groundwater, although the Rockley data do not extend back to this time. 
Figure 2. Chronology of hydrological drought in the Thames at Kingston river flow record. Drought development (grey) and drought terminations (black) are shown.

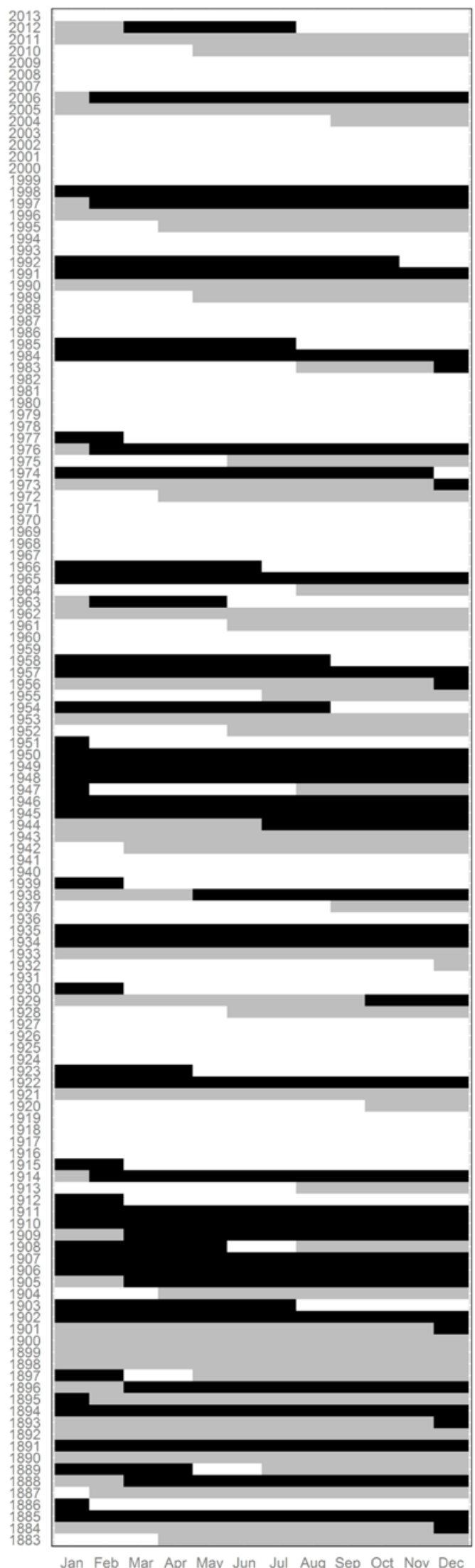

Figure 3. Chronology of groundwater drought in the Rockley borehole level record. Drought development (grey) and drought terminations (black) are shown.

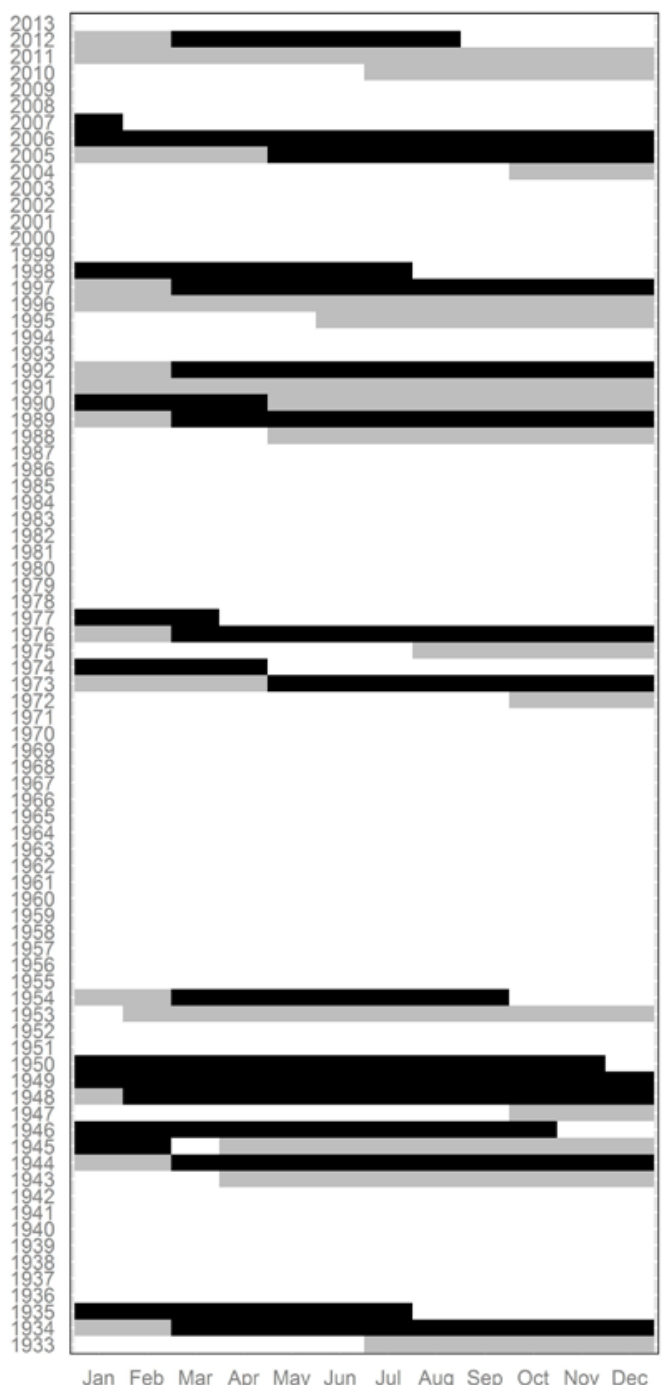

Table 1. Top 5 most abrupt drought terminations for the Thames at Kingston.

\begin{tabular}{|l|r|r|}
\hline Termination & \multicolumn{1}{|l|}{$\begin{array}{l}\text { Duration } \\
\text { (months) }\end{array}$} & $\begin{array}{l}\text { Rate } \\
\text { (\%/month) }\end{array}$ \\
\hline \hline $\begin{array}{l}\text { Mar 2012 - } \\
\text { Jul 2012 }\end{array}$ & 5 & 46.75 \\
\hline $\begin{array}{l}\text { Dec 1973 - } \\
\text { Nov 1974 }\end{array}$ & 12 & 19.97 \\
\hline $\begin{array}{l}\text { Oct 1929 - } \\
\text { Feb 1930 }\end{array}$ & 5 & 16.91 \\
\hline $\begin{array}{l}\text { Feb 1963 - } \\
\text { May 1963 }\end{array}$ & 4 & 16.43 \\
\hline $\begin{array}{l}\text { Jan 1891 - } \\
\text { Dec 1891 }\end{array}$ & 12 & 13.24 \\
\hline
\end{tabular}


Systematic analyses of drought termination have not been conducted for the UK previously which makes validation more difficult. The rapid termination of the 2010-2012 drought through the spring and summer of 2012 (Parry et al. 2013) is captured by both chronologies. The significance of the drought termination in 2012 is underlined by a rate metric value for Kingston that is more than twice as large as that for any previous termination (Table 1). Rapid recovery of river flows following drought conditions has been reported for 1929, 1959, 1963, 1976 (Doornkamp et al. 1980), 1989 and 1992 (Parry et al. 2013). With the exception of 1989, each of these events is captured in Figure 2. The chronologies also detect other termination episodes which are less abrupt (e.g. 1948-1950, 1997-1998, 2006). The systematic analysis presented in this study has enabled the identification of various types of recovery, and additional research is required to understand the physical processes associated with these different events.

\subsection{Comparing hydrological and groundwater termination}

Examination of the overlapping period of river flow and groundwater data (1933-2013) suggests the start and end points of both drought and termination phases for groundwater are lagged behind those for river flow. This is particularly the case for more recent events during 2004-2006 and 2010-2012. The absence of the 1962-1964 and 1984 droughts (and therefore their terminations) from the groundwater chronology in Figure 3 is related to the characteristics of these particular events. The 1962-1964 drought was a succession of dry winters followed by moderately wet springs and summers (Parry et al. 2012); the start of drought criterion (an 18month period with no more than three individual months above the threshold) was not satisfied for Rockley in 1962-1964. The 1984 drought was a summer event predominantly focused on northern and upland areas of the UK, which had little effect on groundwater-influenced catchments in the low-lying south-east of England. The combined duration of pairs of drought and termination periods tend to be shorter for the Rockley level data than for the Kingston flow data. This reflects the earlier onset of hydrological drought, but also that termination phases appear to be shorter for groundwater than for river flow, despite often commencing later. This may be related to the attenuated response of the Chalk aquifer to infiltrating rainfall, with groundwater more likely than surface water to stay consistently above average for a given period of time without interruption. The differing spatial scales represented may also be a factor. The Rockley borehole measures a small part of the Chalk aquifer, whereas the Kingston river flow record integrates over a large catchment area which incorporates a variety of responsiveness of Chalk, in addition to other geologies (e.g. limestones and clays). The location of the Rockley borehole is also important, in the headwaters of the Thames catchment. It is possible that Rockley terminated earlier because the flows in the Thames are reliant on the recovery of groundwater levels from higher up in the catchment, at Rockley and elsewhere.

\subsection{Sensitivity of methodology}

The chronologies for the Thames catchment in Figure 2 and Figure 3 are sensitive to the values of the criteria outlined in Section 3. The number of time steps for a drought to start and the number of time steps for the termination to end, in particular, are likely to be site-specific, influenced by catchment and aquifer characteristics (including area), and rainfall regime. Increasing or decreasing these values will impact the duration of droughts identified, 'pooling' shorter events into longer episodes. For example, in catchments such as the Thames with a significant groundwater influence that provides a buffer against short-term rainfall deficiencies, a smaller value for the start of drought criterion may identify an unrealistically large number of 'drought' periods. Conversely, more responsive catchments may be vulnerable to rainfall deficits over as little as three to six months. Each application of the method will require a systematic analysis of the most appropriate values for the specific context in which it is applied.

\section{CONCLUSIONS}

A new approach has been developed to systematically define and characterize drought termination, and has been applied to long records of river flows and groundwater levels in the Thames 
catchment. The Thames catchment has been selected because it contains long river flow and groundwater level records that best illustrate the utility of the methodology in constructing a chronology of drought termination that places contemporary events into their long-term historical context. It is recognized that this catchment, the largest in the UK, integrates a range of characteristics (such as geology and land use) and physical processes. Future applications of the method will analyze drought termination in smaller, near-natural catchments in order to better understand the physical processes that underpin drought termination. There is also a need to test the transferability of the method in a range of hydroclimatic regimes and catchment types.

The method adequately reproduces the distribution of drought termination episodes in the historical record, and allows the quantification of characteristics (e.g. rate of change) that has not been previously possible. The use of long records maximizes the number of drought terminations that can be characterized and has the potential to improve our process understanding and the spectrum of potential outcomes in a monitoring and forecasting context. The application to two different data types suggest that the transferability of the method could be useful in investigating the complexities of propagation of drought termination through the hydrological cycle.

\section{REFERENCES}

Alexander, LV, \& Jones, PD (2001) Updated precipitation series for the UK and discussion of recent extremes. Atmospheric Science Letters, 1(2), 142-150.

Bayliss, A, Norris, J, \& Marsh, T (2004) The Wendover Springs record: An insight into the past and a benchmark for the future. Weather, 59(10), 267-271.

Bonsal, BR, Wheaton, EE, Meinert, A, \& Siemens, E (2011) Characterizing the Surface Features of the 1999-2005 Canadian Prairie Drought in Relation to Previous Severe Twentieth Century Events. Atmosphere-Ocean, 49(4), 320-338.

Byun, HR, \& Wilhite, DA (1999) Objective Quantification of Drought Severity and Duration. Journal of Climate, 12, 2747-2756.

Dettinger, MD (2013) Atmospheric Rivers as Drought Busters on the US West Coast. Journal of Hydrometeorology, 14(6), 1721-1732.

Doornkamp, JC, Gregory, KJ, \& Burn, AS (1980) Atlas of drought in Great Britain. Institute of British Geographers, London.

Hannaford, J, \& Buys, G (2012) Trends in seasonal river flow regimes in the UK. Journal of Hydrology, 475, 158-174.

Heim Jr., RR, \& Brewer, MJ (2012) The Global Drought Monitor Portal: The Foundation for a Global Drought Information System. Earth Interactions, 16(15), 1-28.

Jones, PD, Lister, DH, Wilby, RL, \& Kostopoulou, E (2006) Extended riverflow reconstructions for England and Wales, 1865-2002. International Journal of Climatology, 26, 219-231.

Kam, J, Sheffield, J, Yuan, X, \& Wood, EF (2013) The Influence of Atlantic Tropical Cyclones on Drought over the Eastern United States. Journal of Climate, 26, 3067-3086.

Kendon, M, Marsh, T, \& Parry, S (2013) The 2010-2012 drought in England and Wales. Weather, 68(4), 88-95.

Manley, G (1974) Central England Temperatures: monthly means 1659-1973. Quarterly Journal of the Royal Meteorological Society, 100(425), 389-405.

Marsh, T, Cole, G, \& Wilby, R (2007) Major droughts in England and Wales, 1800-2006. Weather, 62(4), 87-93.

Marsh, T, \& Harvey, CL (2012) The Thames flood series: a lack of trend in flood magnitude and a decline in maximum levels. Hydrology Research, 43(3), 203-214.

Mo, KC (2011) Drought onset and recovery over the United States. Journal of Geophysical Research, 116, D20106.

Panu, US, \& Sharma, TC (2002) Challenges in drought research: some perspectives and future directions. Hydrological Sciences Journal, 47(S), S19-S30.

Parry, S, Hannaford, J, Lloyd-Hughes, B, \& Prudhomme, C (2012) Multi-year droughts in Europe: analysis of development and causes. Hydrology Research, 43(5), 689-706. 